\title{
Bargains and Ripoffs: A Model of Monopolistically Competitive Price Dispersion
}

\author{
STEVEN SALOP \\ Federal Reserve Board \\ and \\ JOSEPH STIGLITZ \\ Stanford University and Oxford University
}

\section{INTRODUCTION}

This paper analyses an economy in which agents differ in their ability and willingness to make economical decisions in the market-place. On the one hand there are economists, the information required to make wise pus consumers who carefully and analytically gather lating in their decisions. Most people doses. Other agents are less rational and calcuprobability; for example, an overwhelming not understand even the simplest laws of "tails" in a coin-ffipping game. Many peoplerity will bet "heads" after a run of market. Disparity in incomes provides some do not calculate unit-prices in the superdifferences in preference or ability, some agents perform much better than others in market
decisions.

We explore this problem of heterogeneity of con model of costly information-gathering. We ass of consumer rationality within a simple of becoming perfectly informed. To make the mume that consumers differ in the "costs" the relevant information to gather and the flow ofel as simple and transparent as possible, oversimplified: only price information is gathered information is highly unrealistic and limited prior information; "perfect" informatiod; consumers have "rational " though However, the model may be reinterpreted to in may be generated for some fixed cost. differentials and heterogenous commodity include the more realistic cases of quality transmission such as sequential search, advertisingences and more complex information

The central implication of search, advertising and word-of-mouth.

occur at the perfectly competitive price Suppose every firm did charge the perfectly com is a fairly straightforward observation: raise price slightly without losing any customers. Coive price. Then some firm(s) could the extra information needed to switch stores. Consumers would be unwilling to gather price increases at one store that consunstor or brands. Clearly there is a limit on the the relative store prices determine the gains will tolerate without leaving. However, since slightly, the cycle of price rises by a few stores m search, then as every store raises price the market continue to rise.

Akerlof's famous " Lemons Priniple" [1] (or quality fall) until the market is destroyed [1] asserted that prices will continue to rise settle down at the pure monopoly price with each Diamond [4] realized that the prices may 
over its usual customers. In our model, we show that the market will not be destroyed, for, when prices get high enough, some firm can lower its price substantially and induce search. At this point there are two possibilities; either prices may cycle forever, or they may settle down to some equilibrium configuration.

We show that if prices do settle down, they will settle at the monopoly price (or, as Braverman [2] has pointed out, at a Chamberlinean monopolistically competitive price) or there may be permanent price dispersion in the range between the perfectly competitive and monopolistically competitive prices. The final spread of prices depends on the magnitude of information costs and degree of scale economies. For U-shaped average costs, higher-priced firms produce in the region of decreasing average costs; thus, there are too many small firms at equilibrium.

Moreover, the economy does not produce information efficiently. A " rational economic planner" could economize on information costs by eliminating the price dispersion; for with no price dispersion, there is no need for costly search. There is an informational externality at work between efficient and inefficient information-gatherers. Those agents who become informed give an external economy to the uninformed; the weight of their search keeps prices lower. In fact, if there are enough informed agents, the market price will settle down to the perfectly competitive price. On the other hand, by shopping at high-priced stores, the uninformed inflict an external diseconomy on the informed; these informed must gather costly information to obtain the lower price.

In this paper, a simplistic market with costly information-gathering for complete price-information will be studied. We will analyse an example in which there are only two groups of consumers by search costs. Four Nash equilibrium configurations can occur in this market:

(i) A Single-Price Equilibrium (SPE) at the Competitive Price, $p^{*}$.

(ii) A Single-Price Equilibrium at the Monopoly Price, $u$.

(iii) A Two-Price Equilibrium (TPE) in which the lower price, $p_{l}$, is the competitive price, and the higher price, $p_{b}$, is no greater than the monopoly price.

(iv) Non-existence of any Nash equilibrium.

Regions in which the four cases obtain are shown in Figure 1.

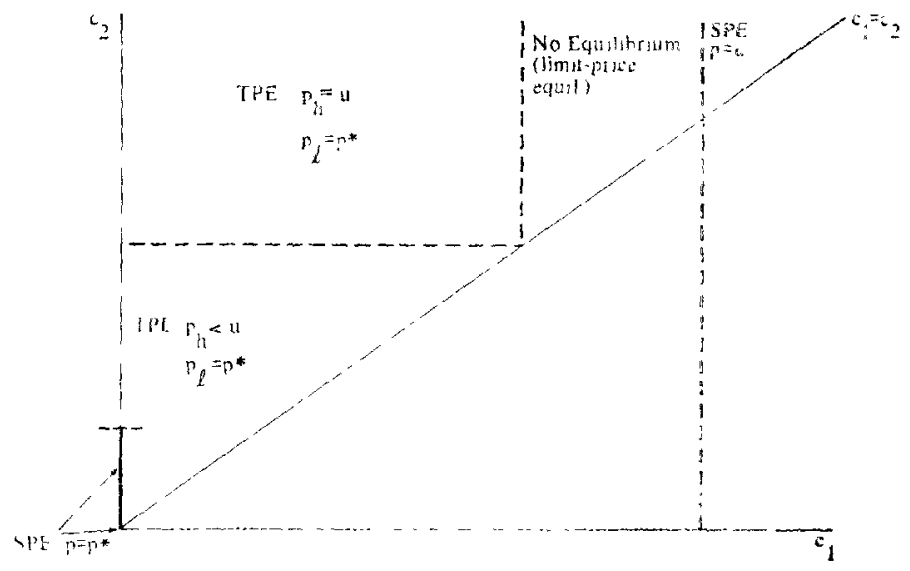

Figure 1 


\section{FORMAL MODEL}

There are a large number, $L$, of consumers who form the potential market for a durable commodity. Each consumer has an identical inelastic demand curve for one and only one unit of the commodity. The maximum price a consumer will pay (the reservation price) is denoted by $u^{1}$; hence, $u$ is the monopoly price. This assumption is made for simplicity; it has been generalized to downward sloping demand curves by Braverman [2].

The most crucial assumptions of the model are those describing the consumers' degree of information and the corresponding information flows among consumers and firms. In the formal model here, the commodities sold at the different stores are known by consumers to be identical. However, consumers do not have perfect information regarding the price charged at each store in the market; this information must be generated at a cost. Suppose there are $n$ stores selling the commodity at prices $p=\left\{p_{1}, p_{2}, \ldots, p_{n}\right\}$ at locations $\underline{l}=\left\{l_{1}, l_{2}, \ldots, l_{n}\right\}$. The usual competitive model assumes that consumers are freely endowed with perfect information regarding the $\{p, \underline{l}\}$ set. This model will move only one step from perfect information. We will assume that the consumer is freely endowed with the price vector $p$; he knows the prices charged in the market. However, he does not know a priori the location vector $\underline{l}$ of these prices. That is, he knows what prices exist but he does not know which store charges which price. Clearly much of the information-gathering in markets attempts to discover locations, quality and other product characteristics as well as price. However, each of these variables affects the "effective" price a consumer pays per unit of a standard commodity bundle. The model could be generalized into a Lancasterian hedonic-price framework in which information increases a consumer's " net surplus".

We will assume that only complete information may be gathered: Consumer $i$ may gather complete information regarding the $\underline{l}$-vector for a fixed cost $c^{i}$. Once $\underline{l}$ is known, he can then go costlessly to the minimum-price store and purchase the commodity there. This assumption could be thought of as follows: A newspaper exists that publishes full information; consumer $i$ can purchase and process all the information in the newspaper for a cost $c^{i}$. Consumers differ in their information-gathering costs due to differences in analytic ability, the cost of time and preference for reading and processing information.

This complete information assumption is the central one in the model. It will be seen that it does generalize to include fixed-cost advertising. However, partial processing of information which generalizes to variable search costs (sequential search) and variable advertising costs lead to quite different results. ${ }^{2}$ It is assumed that sequential sampling is quite costly and not economical for consumers to pursue.

Finally, we make the simplest assumption that there are only two groups of consumers distinguished by information-generating costs, a proportion, $\alpha$, with cost $c_{1}$ and the rest, $(1-\alpha)$, with higher cost $c_{2}$; this assumption is made for analytic convenience only, it is not crucial to any of the results obtained. For models with a continuous cost distribution, see Salop and Stiglitz [12] and Braverman [2].

The consumer has two decisions to make. He must decide whether to enter the market at all. He must also decide whether to buy the newspaper to obtain perfect information or purchase at a randomly selected store. We will first analyse the information-gathering decision.

If consumer $i$ buys the newspaper at cost $c^{i}$, he will be able to purchase at the lowest available price, which we denote by $p^{\mathrm{min}}$. His total expenditure will be $E_{S}^{i}$ where

$$
E_{S}^{i}=p^{\min }+c^{i}
$$

Alternatively, he can purchase at a randomly selected store and on average pay a price equal to the mean price charged, $\bar{p}$. Thus, the total expected expenditure from the nosearch strategy, $E_{N}^{i}$, is

$$
E_{N}^{i}=\bar{p}=(1 / n) \sum_{j=1}^{n} p_{j}^{3}
$$


Assuming the consumer is risk-neutral, ${ }^{4}$ he will buy the newspaper if and only if

$$
E_{S}^{i}<E_{N}^{i},^{5} \Leftrightarrow p^{\text {min }}+c^{i}<\bar{p}
$$

Having decided on the optimal search strategy, a consumer will enter the market if and only if his total cost does not exceed his demand price, $u$, i.e. if and only if

$$
u \geqq \min \left[p^{\min }+c^{i}, \bar{p}\right] \text {. }
$$

It is also true that no consumer will pay a price greater than $u$. Thus, a store charging a price greater than $\|$ will obtain no sales at all.

There are $n$ firms selling the durable commodity. Every firm has identical technology characterized by a fixed cost $T$ and variable costs $v(q)$ which depend on the quantity $q$ produced. Marginal cost is assumed to be increasing $\left(v^{\prime}(q)>0\right)$. Thus, the average cost $(A C)$ curve is $U$-shaped.

Firms do not have the information problem facing consumers. Like consumers, they are assumed to know the prices charged by other firms; they need not know the actual locations of other firms. Furthermore, we assume they know costlessly the distribution of consumers' search costs and thus can perfectly predict how many consumers will search. This is the information that is necessary for each firm to know its expected demand curves. $L$ is assumed large enough for the law of large numbers to assure that actual demand always equals expected demand. Thus, firms face no uncertainty or any critical shortage of information.

It is assumed that firms follow "Nash" price-setting behaviour vis-à-vis other firms. That is, a firm takes all other firms' prices as given in maximizing its profits. Formally, for firm $j$, we have

$$
\max _{p} \pi^{j}\left(p \mid \underline{p}^{-j}\right), \underline{p}^{-j}=\left\{p_{1}, p_{2}, \ldots, p_{j-1}, p_{j+1}, \ldots, p_{n}\right\}
$$

On the other hand, each firm follows a "Stackleberg" strategy vis-à-vis consumers. Rather than taking the consumer search decisions as given, it takes the consumer search rule as given and takes into consideration exactly how consumer search decisions will depend on the price it chooses. More precisely, the firm knows that an individual with $\operatorname{cost} c^{i}$ will search if

$$
c^{i}<\bar{p}-p^{\min }
$$

Firm $j$ calculates its effect on $\bar{p}$ and $p^{\min }$ in the following way.

$$
\begin{aligned}
\bar{p} & =\frac{1}{n} p_{j}+\frac{1}{n} \sum_{i \neq j} p_{i} \\
p^{\min } & =\min \left\{p_{j}, p^{-j}\right\}
\end{aligned}
$$

From these three equations and the distributions of consumers by informationgathering costs, we may calculate the demand curve for firm $j$ given the prices of the other $(n-1)$ firms. We denote this demand curve by $D\left(p_{j} \mid p^{-j}\right)$. Note how the Nash and Stackleberg assumptions are contained in the demand curve. Firm $j$ takes the other firms' prices $p^{-j}$ as given. However, it considers how its price choice induces informationgathering by consumers.

Finally, we assume that entry occurs as long as profits are positive. This assumption assures that at equilibrium (if one exists), every firm makes identical zero profits. That is, denoting by $\hat{p}_{j}$ the price of firm $j$ that comes from its profit-maximizing behaviour and by $\hat{p}^{-j}$ the other firms' optimal prices, we have

$$
\pi\left(\hat{p}_{j} \mid \hat{p}^{-j}\right)=0, \text { for all } j=1,2, \ldots, n .
$$

This condition is used to compute the number of firms in equilibrium. It simply states that in equilibrium price equals average cost for each firm. ${ }^{6.7}$ This is, of course, the monopolistic competition assumption. 
Equilibrium. Given the assumptions just made, we may characterize the monopolistically competitive equilibrium in this market. An equilibrium is defined by a price vector $p^{*}=\left\{p_{1}^{*}, p_{2}^{*}, \ldots, p_{n}^{*}\right\}$, a number $n^{*}$ of firms in the market, and a percentage of consumers that gather information $a^{*}$ that obey the following conditions:

(i) Profit Maximization. Each firm chooses a price to maximize its profits given the prices of the other firms and the search strategy of consumers summarized in its demand curve. For every firm $j$, we have

$$
\max _{p} \pi\left(p_{j} \mid p^{*-j}\right)=p_{i} D\left(p_{j} \mid \underline{p}^{*-j}\right)-v\left[D\left(p_{j} \mid \underline{p}^{*-j}\right)\right]-T, \text { for all } j=1,2, \ldots, n^{*}
$$

(ii) Zero Profits. Furthermore, the maximizes value of profifs tor every firm $j$ equals zero at equilibrium.

$$
\pi\left(p_{j}^{*} \mid \underline{p}^{*-j}\right)=0, \text { for all } j=1,2, \ldots, n^{*} .
$$

Thus, an equilibrium is characterized by $n^{*}$ firms charging identical or different prices and each producing and selling just enough output to place them on the downward sloping portion of their common average cost curve, with enough firms so that every customer obtains one unit of the commodity. Note that the zero profit and profit-maximization conditions jointly imply that each firm's demand curve lies below the $A C$-curve at every point except the equilibrium price chosen.

(iii) Search Equilibrium. At equilibrium, consumers gather information optimally.

$$
\alpha^{*}=\left\{\begin{array}{l}
1 \text { for } c_{1} \leqq c_{2}<\bar{p}-p^{\min } \\
\alpha \text { for } c_{1}<\bar{p}-p^{\text {min }} \leqq c_{2} \\
0 \text { for } \bar{p}-p^{\min } \leqq c_{1} \leqq c_{2}
\end{array}\right.
$$

\section{OVERVIEW OF THE MODEL}

Before turning to the technical details, it may be useful to summarize the argument in a more intuitive way. The basic TPE is pictured below: high-price, $p_{h}$, stores sell a smaller quantity, $q_{h}$, than do lower-priced, $p_{l}$, stores. Every store earns zero profits, $p=A C$. The TPE has the properties that: (a) the higher information-cost consumers $[(1-\alpha) L$ consumers with cost $c_{2}$ ] choose to remain uninformed given the price dispersion in the market; they purchase randomly from the first store sampled, while (b) the lower informationcost consumers $\left[\alpha L\right.$ consumers with cost $\left.c_{1}<c_{2}\right]$ choose to become informed, and hence purchase from a $p_{l}$ store. This property constrains the possible price dispersion in the market.

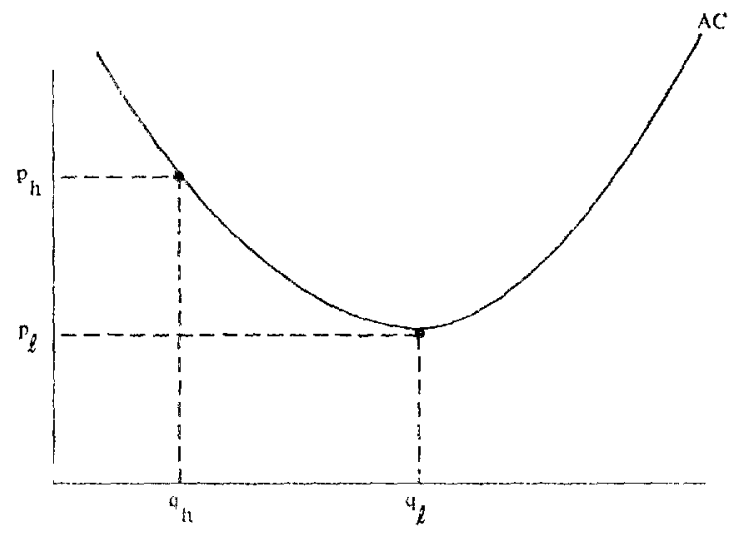

FIGURE 2 
If a proportion, $\beta$, of the total stores, $n$, is low priced, and if consumers search optimally, it must be true that $c_{1}<(1-\beta)\left(p_{h}-p_{l}\right) \leqq c_{2}$, (where the expected gains from search are $(1-\beta)\left(p_{h}-p_{i}\right)$, and costs are $c_{i}$ for a type-i consumer).

Given that only the $c_{1}$ 's become informed, $p_{h}$ stores sell only to uniucky uninformed consumers while $p_{l}$ stores sell to informed consumers and lucky uninformed consumers. As there are $(1-\beta)(1-\alpha) L$ unlucky $c_{2}$ 's and $(1-\beta) n$ high-priced stores we have

$$
q_{h}=(1-\alpha) \frac{L}{n}
$$

As each low-priced store gets a normal $(1 / n)$ th share of the $(1-\alpha) L$ uninformed $c_{2}$ 's and additionally the $\beta n$ low-priced stores split the $\alpha L$ informed $c_{1}$ 's equally, we have

$$
q_{l}=(1-\alpha) \frac{L}{n}+\frac{\alpha L}{\beta n}
$$

Denoting the downward-sloping portion of the average cost curve by $A C=A(q)$, zero profits implies

$$
\begin{aligned}
& p_{h}=A\left(q_{h}\right) \\
& p_{l}=A\left(q_{l}\right) .
\end{aligned}
$$

The low price must equal the competitive price $p^{*}$. Otherwise, one low-priced store could shade its price slightly, obtain all the informed customers and even positive profits. Thus, we have

$$
p_{l}=p^{*}
$$

Substituting, we have the equilibrium conditions

$$
\begin{aligned}
p^{*} & =A\left[\left(\frac{\alpha}{\beta}+(1-\alpha)\right) \frac{L}{n}\right] \\
p^{*}+\frac{c_{2}}{1-\beta} & =A\left[(1-\alpha) \frac{L}{n}\right]
\end{aligned}
$$

This is the essence of the model. Complications arise from the possibility of corner solutions and non-existence of a TPE or any equilibrium.

\section{DERIVATION OF EQUILIBRIA}

We will now derive the equilibrium prices for this market. The methodology is as follows. A "potential " equilibrium satisfying the zero profit condition is proposed. We first check to see that the consumer search equilibrium condition is satisfied. Then, we examine the behaviour of a "deviant " firm to see whether its profit-maximization condition is satisfied at the "potential " equilibrium. If a "deviant" firm increases its profits by charging a different price, then the "potential "equilibrium is not an equilibrium. Only if the deviant prefers the equilibrium price is the potential equilibrium an actual equilibrium. This is equivalent to assuming that firms experiment in their pricing decisions. 
Lemma 1. There are no Three-, Four-, .. .-Price Equilibria. Only Single-Priced Equilibria (SPE) and Two-Price Equilibria (TPE) are possible.

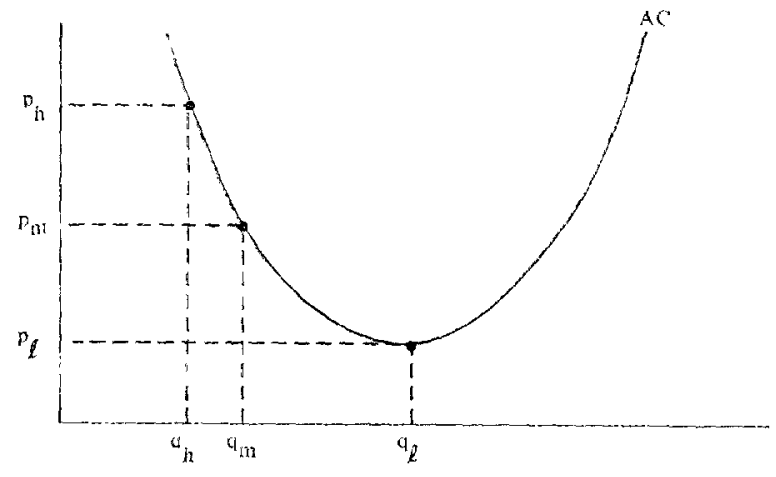

Figure 3

Three-price equilibrium.

Proof. At these prices, suppose some consumers find it worth while to purchase complete information; these consumers pay the low price $p_{l}$. Of those consumers that do not search, every firm obtains an equal $(1 / n)$ th share. Since the $p_{m}$ and $p_{h}$ firms sell only to uninformed consumers, their sales are identical. Thus, the $p_{h}$ firms must obtain higher revenue, breaking the zero profit condition. ${ }^{8}$

This lemma holds for all distributions of consumer search costs, for the consumers can always be split into an informed and an uninformed group. Incomplete informationgathering is necessary for equilibria with more than two prices.

Two-price and single-price equilibria are possible. We will first examine single-price equilibria and show that there may only be single-priced equilibria at the monopoly price $u$ and at the competitive price $p^{*}$.

\section{Single-Price Equilibria}

Lemma 2. There is no single-price equilibrium at any price $\hat{p}$ in the open interval $\hat{p} \in\left(p^{*}, u\right)$.

Proof. Consider a SPE at $\hat{p}$ in the open interval $\left(p^{*}, u\right)$ obeying the zero profit condition as pictured below.

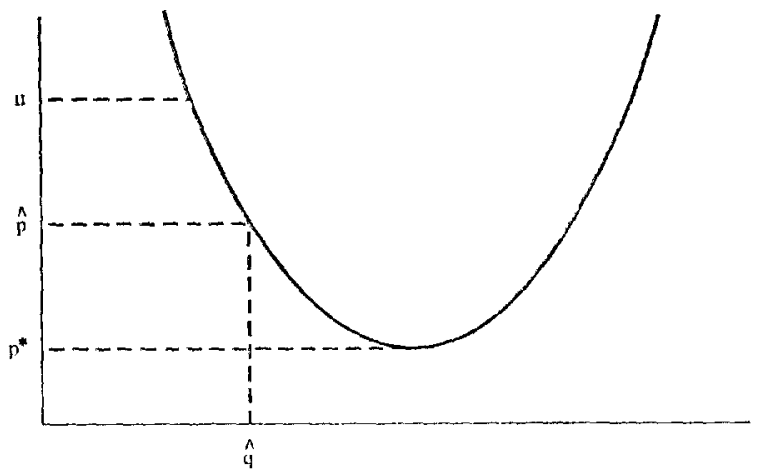

Figure 4

Interior single-price equilibrium. 
Since there is no price dispersion, each of the $n$ frms in production obtains equal sales, or $\hat{q}=L / n$. This defines the potential equilibrium number of firms. We will now show that it always pays a deviant to charge a price different from $\hat{p}$.

(a) Local Price Rises. Suppose a deviant raises his price slightly to $\hat{p}+\varepsilon$. From (9), this raises the mean price to $\bar{p}^{\prime}=\hat{p}+(\varepsilon / n)$. The benefit of search becomes $b=\bar{p}^{\prime}-p^{\text {mia }}$. Since $p^{\min }=\hat{p}$, we have a positive benefit or $b=(\varepsilon / n)$. Consumer $i$ will gather information if and only if $c_{i} \leqq b$.

If $c_{2} \geqq c_{1}>0$, there exists some small $\varepsilon>0$ such that the deviant firm loses no customers; its demand curve is perfectly inelastic for some interval above $\hat{p}$. Thus, if it raises its price, its revenue rises. This breaks the profit-maximization equilibrium condition and thus the potential equilibrium. On the other hand, if $c_{1}=0$, even an $\varepsilon$-price change induces search and may make the deviant strategy unprofitable. However, in that case, price decreases will be profitable.

(b) Local Price Decreases. Suppose a deviant were to lower his price slightly to $\hat{p}-\varepsilon$. From (9) and (10), both $\bar{p}$ and $p^{\text {min }}$ fall. $p^{\min }$ falls by more. Thus, we have

$$
b=\bar{p}^{\prime}-p^{\text {min }}=\frac{n-1}{n} \varepsilon \text {. }
$$

If $c_{1}=0$, those $\alpha L$ type 1 consumers will become informed and buy from the deviant. He will obtain a normal $(1 / n)$ th share of the $(1-\alpha) L$ uninformed type 2's and all the $\alpha L$ informed type 1's. His sales jump from $L / n$ to

$$
q_{d}=(1-\alpha) \frac{L}{n}+\alpha L=\frac{L}{n}+\alpha L\left(\frac{n-1}{n}\right) .
$$

Since his sales jump from this small price decrease, his profits become positive. ${ }^{9}$ Once again, the profit-maximization condition is broken and the potential SPE is impossible.

At the monopoly price $u_{3}{ }^{10}$ the deviant strategy of raising price is not profitable; no consumer is willing to pay a price above $u$. Similarly, at the competitive price $p^{*}$, since $p^{*}=\min A C$, any price decreases must be unprofitable, regardless of the deviant's sales. As a result, there may be SPE's at $u$ and $p^{*}$. We analyse the competitive price first.

Consider the potential SPE at the competitive price $p^{*}$. Zero profits implies that each firm must sell $q^{*}$, as pictured below. Since there is no dispersion, no search takes place at this equilibrium and the number of firms $n^{*}$ is easily $\mathrm{ca}^{1}$ culated from $q^{*}=L / n^{*}$. (Of course, we are assuming $u>p^{*}$. If $u<p^{*}$, no market can exist for this commodity.)

There are two cases in which $p^{*}$ is a full equilibrium. If both groups can gather information costlessly $\left(c_{1}=c_{2}=0\right)$, then if a deviant raises price by $\varepsilon>0$, he loses all his customers. This is the conventional result that the purely competitive price obtains if consumers are perfectly informed. On the other hand, if both groups face costly search $\left(c_{1}, c_{2}>0\right)$, the SPE at $p^{*}$ cannot obtain.

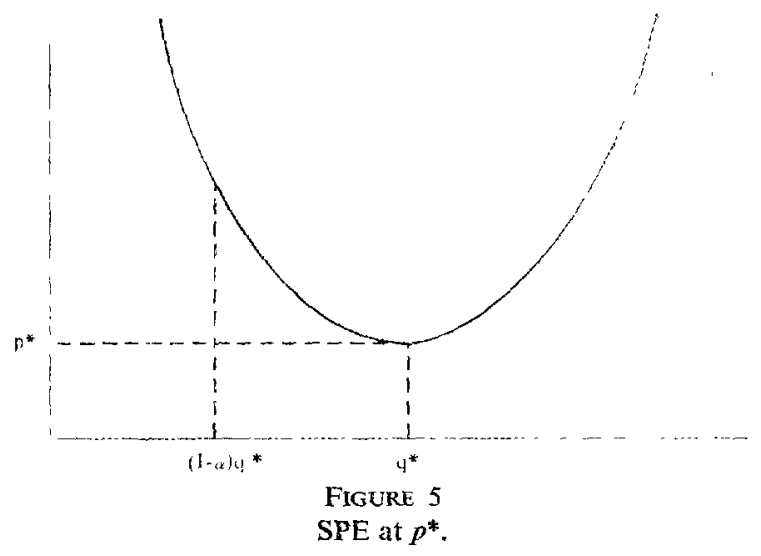


Suppose the type 1's have perfect information $\left(c_{1}=0\right)$, and the type 2's do not $\left(c_{2}>0\right)$. If a deviant raises his price, he will lose all his type 1's and none of his type 2 's. Since he will be earning a higher return on fewer sales, his profits may rise or fall. There is a limit on his price increase: if he chooses $p_{d}>u$, the type 2's will drop out of the market; if he chooses $p_{d}$ such that type 2's find it worth while to gather information, he loses all his customers. If he charges $p_{d}$, the benefit of search is given by

$$
b=\bar{p}^{\prime}-p^{\min }=\frac{1}{n^{*}}\left(p_{a}-p^{*}\right) .
$$

He loses no type 2 customers if he chooses a $p_{d}$ such that $c_{2} \geqq b$ and $p_{d} \leqq u$; that is, if $p_{d} \leqq \min \left[u, p^{*}+n^{*} c_{2}\right]$. Since the proportion of type 2 's is $(1-\alpha)$ his sales will be $q_{d}=(1-\alpha)\left(L / n^{*}\right)$. Since $q^{*}=L / n^{*}$, we have $q_{d}=(1-\alpha) q^{*}$. This deviant strategy will be profitable if $A\left(q_{d}\right)$, the average cost of producing $q_{d}$, is less than the price $p_{d}$. Thus, the SPE is not broken if and only if

$$
A\left[(1-\alpha) q^{*}\right]>\min \left(u, p^{*}+n^{*} c_{2}\right) \text {. }
$$

(22) will hold for small $u$ and $c_{2}$, for steep $A C$ curves, and most crucially, for large $\alpha$. This formalizes a notion that has always been implicit in competitive theory: Every consumer need not have perfect information. If there are enough perfectly informed consumers ( $\alpha$ high enough), the weight of their potential search keeps the market competitive. The informed exert a positive pecumiary externality on the uninformed. As we shall see subsequently, this externality remains even when there is a price dispersion at equilibrium.

We now analyse the conditions under which a SPE obtains at the monopoly price $u$. If there is a SPE at $u$, every firm produces a quantity $q_{a}$ as shown in Figure 6.

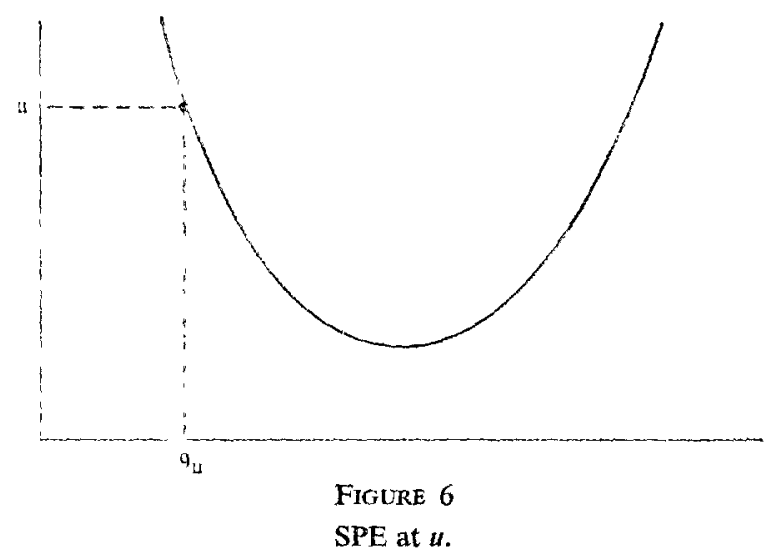

As we argued previously, no firm will raise its price, for no consumer will pay more than u. If a deviant were to lower price to $p_{d}<u$, he lowers the minimum price more than he owers the mean price. Since $\bar{p}^{\prime}=((n-1) / n) u+(1 / n) p_{d}$, and $p^{\min \prime}=p_{d}$, the benefit of search rises to

$$
b=\bar{p}^{\prime}-p^{\text {min }}=\frac{n-1}{n}\left(u-p_{d}\right) .
$$

If $b \geqq c_{1}$, the type 1's will search and the deviant's sales will jump to

$$
a_{d}=(1-\alpha) \frac{L}{n}+\alpha L=(1-\alpha) q_{u}+\alpha L
$$

For large values of $L,{ }^{\mathbf{1 1}}$ this will be a profitable strategy if and only if

$$
p_{d} \geqq p^{*} \text {. }
$$


That is, a deviant firm can induce search by lowering price, but this will only lead to positive profits if the "search-inducing price", $p_{d}$, is above the competitive price. Setting $c_{1}=b$, we have the condition that this SPE is a full equilibrium if and only if

or

$$
p_{d}=u-(n /(n-1)) c_{1}<p^{*}
$$

$$
u-p^{*}<\frac{n}{n-1} c_{1}
$$

For $L \rightarrow \infty$, then $n \rightarrow \infty$ and we have

$$
u-p^{*} \approx c_{1} \leqq c_{2}
$$

This condition makes intuitive sense. If the deviant lowers price to $p^{*}$, the gains from search are (approximately) $u-p^{*}$. If the cost, $c_{1}$, of informing the type 1 's of its location outweighs the benefit, the deviant will not induce search.

\section{Two-Price Equilibria (TPE)}

For the $\left(c_{1}, c_{2}\right)$ discussed above, a SPE will obtain. For all other values of $\left(c_{1}, c_{2}\right)$ either a TPE or no Nash-equilibriun obtains. The interaction between the three equilibrinita conditions is seen most clearly in the analysis of a TPE. We will adopt the following notation. An equilibrium will be defined by a number of firms, $n$, of which a proportion, $\beta$, charge a low price, $p_{l}$, and the rest, a proportion $(1-\beta)$, charge a high price, $p_{h}$. A TPE with the property that $p_{l}=p^{*}$ was pictured previously in Figure 2.

(i) Search Equilibrium. For a TPE to obtain, it must be true that only those lower cost consumers become informed. (If all or none of the consumers become informed. every firm will obtain identical sales.) From the search rule in $(6)$, we have the necessary condition

$$
c_{1}<\bar{p}-p^{\mathrm{ain}} \leqq c_{2}
$$

Substituting the definition of $\bar{p}, \bar{p}=\beta p_{l}+(1-\beta) p_{h}$, we have

$$
c_{1} \leqq(1-\beta)\left(p_{h}-p_{l}\right) \leqq c_{2} .
$$

(ii) Zero Profits. Each of the $n$ firms must earn zero profits. Given (25) the $p_{h}$ frms sell only to uninformed consumers; the sales per firm- $g_{h}$ is given by

$$
q_{h}=(1-\alpha) \frac{L}{n} \text {. }
$$

The $p_{l}$ firms obtain an identical share of the uninformed and shate the informed consumers among themselves. Thus $\beta n$ firms split up $\alpha L$ informed consumers, and each gets $\alpha L / \beta n$ of them. Each has sales given by

These sales must yield zero profits:

$$
q_{l}=\left(1-\alpha+\frac{\alpha}{\beta}\right) \frac{L}{n} .
$$

$$
\begin{aligned}
& p_{h}=A\left((1-\alpha) \frac{L}{n}\right) \\
& p_{l}=A\left(\left(1-\alpha+\frac{\alpha}{\beta}\right) \frac{L}{n}\right),
\end{aligned}
$$

where $A(q)$ is average costs.

(iii) Maximum Profits. As kefore, no deviant must be willing to break the TPE by charging a different price, either locally or globally. This consideration permits the following two Lemmas to be proved.

Lemma 3. $p_{l}=p^{*}$. The low price is the competitive price. 
Proof. The proof of this proposition is straightforward. Consider a TPE in which $p_{l}>p^{*}$. If a deviant $p_{l}$ firm were to shade its price slightly, it would obtain all the informed customers instead of only a proportion $(1 / \beta n)$ of them. Its sales would jump and its profits would become positive. On the other hand, if $p_{l}=p^{*}$, then the deviant makes negative profits from price shading, regardless of the number of customers it obtains.

Lemma 4. $p_{l}=\min \left[u, p_{l}+\left(c_{2} /(1-\beta)\right)\right]$. Referring to $(25)$, the high price is either the monopoly price or just high enongh that the type 2's are indifferent between becoming informed and purchasing randomly.

Proof. Suppose $p_{h}<p_{1}+\left(c_{2} /(1-\beta)\right)$, that is, suppose $(1-\beta)\left(p_{h}-p_{l}\right)<c_{2}$. Then from (25), it is clear that the type 2 consumers prefer not to search. Thus, a deviant $p_{h}$ frrm could raise its price, lose no customers and increase its profits; this would break the TPE. Only if a deviant $p_{h}$ firm loses its uninformed customers from price rises can the TPE obtain. This occurs only if small price rises induce them to exit from the market $\left(p_{h}=u\right.$ ) or induce them to search, $\left(p_{h}=p^{*}+\left(c_{2} / 1-\beta\right)\right)$. Note that we follow the convention that if a consumer is indifferent between searching and purchasing randomly, he follows the latter strategy.

Substituting into (28) and (29) the results of Lemmas 3 and 4 for $p_{l}$ and $p_{h}$, we summarize the TPE as follows:

$$
\begin{aligned}
A\left((1-\alpha) \frac{L}{n}\right) & =\min \left(u, p^{*}+\frac{c_{2}}{1-\beta}\right) \\
A\left(\left(1-\alpha+\frac{\alpha}{\beta}\right) \frac{L}{n}\right) & =p^{*} .
\end{aligned}
$$

Further, since $p^{*}=A\left(q^{*}\right)$, we have

$$
q^{*}=(1-\alpha-(\alpha / \beta))(L / n)
$$

Equations (30) and (31) may be solved for the equilibrium values of $\beta$ and $n$. Note we also have the implicit constraint $0<\beta<1$.

A solution to these equations is a full equilibrium only if no firm can earn positive profits from globally deviating by charging a different price, for Lemmas 3 and 4 were local conditions only, and global deviance must also be checked. We will now solve (30)-(31) for $\beta, n$, and then check on globally deviant behaviour. We will find that profitable global deviance sometimes breaks the equilibrium.

The clearest method of the solution is to diagramme equations (30)-(32). Equation (31) is illustrated in Figure 7. It is easy to show the curve is downward sloping, since $d^{*} \beta / d n=-\left(\beta^{2} / n \alpha\right)(1-\alpha-(\alpha / \beta))<0$, where $(\alpha / \beta)>\alpha$ since $\beta<1$.

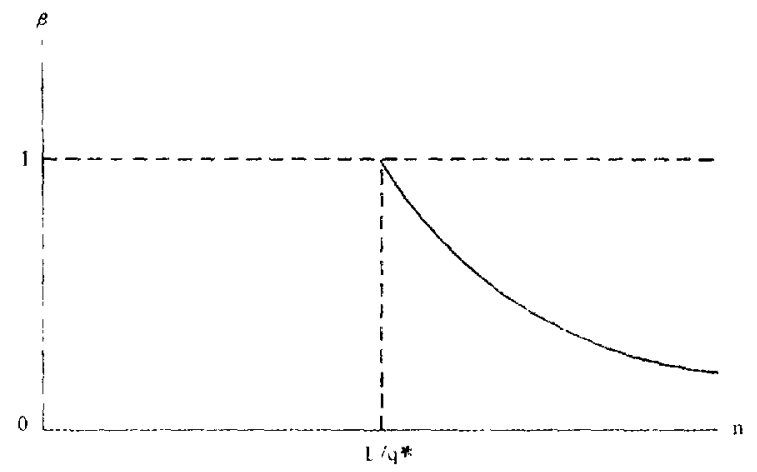

FIGURE 7

$\pi_{l}=0$. 
From (31), when $\beta=1, A(L / n)=p^{*}$. From (32), we have $p^{*}=A\left(q^{*}\right)$, and, when $\beta=1, n=L / q^{*}$ where $q^{*}$ is the minimum average cost quantity.

The diagram of equation (30) is more difficult. There are two regions, depending on whether $u$ or $p^{*}+\left(c_{2} /(1-\beta)\right)$ is smaller. The boundary $(\hat{\beta})$ of these two regions may be positive or negative. Setting the two terms equal, we have

Setting $\hat{\beta} \gtreqless 0$, we have

$$
\grave{\beta}=1-\frac{c_{2}}{u-p^{*}} .
$$

$$
\hat{\beta} \lesseqgtr 0 \Leftrightarrow c_{2} \gtreqless u-p^{*} \text {. }
$$

There are two $\beta$-regions to consider:

Region $I\left(\beta<1-c_{2} /\left(u-p^{*}\right)\right)$. In this region, $p^{*}+\left(c_{2} /(1-\beta)\right)$ is smaller, and the $\beta-n$ curve is upward sloping, since $d \beta / d n=-(1-\beta)^{2} L(1-\alpha) A^{\prime} /\left(c_{2} n^{2}\right)>0$. It is described by

$$
p^{*}+\frac{c_{2}}{1-\beta}=A\left((1-\alpha) \frac{L}{n}\right)
$$

The curve is asymptotic (as $\beta \rightarrow-\infty)$ to $n=(1-\alpha)\left(L / q^{*}\right)$, from (32).

Region $I I\left(\beta \geqq 1-c_{2} /\left(u-p^{*}\right)\right)$. In this region, $u$ is the minimum, and the equation is described by

$$
u=A\left((1-\alpha) \frac{L}{n}\right) .
$$

Defining the quantity on the average cost curve at $u$ by $q_{w}$, we have

$$
q_{u}=(1-\alpha) \frac{L}{n}
$$

which defines an $n_{u}$ such that

$$
n_{u}=(1-\alpha) \frac{L}{q_{u}}
$$

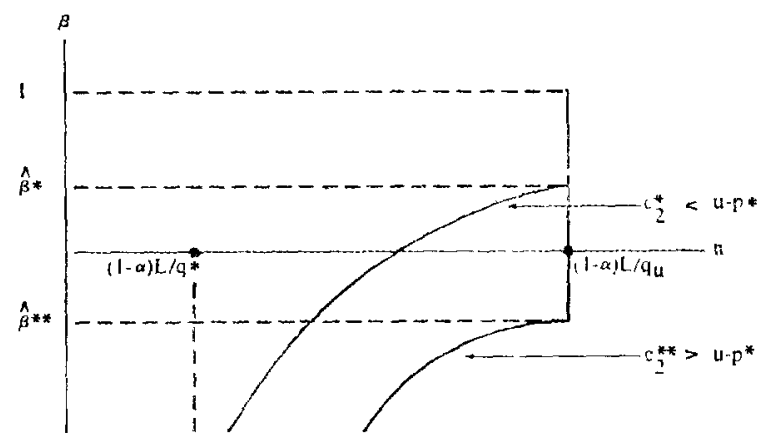

FIGURE 8

$$
\pi_{k}=0 \text {. }
$$

Equation (30) is shown in Figure 8 for two values of $c_{2}$. Possible TPE's occur where the curves cross. Noting that the minimum $n$ in Figure 7 is $L / q^{*}$ and maximum $n$ in Figure 8 is $(1-\alpha) L / q_{u}$, then a necessary condition for a TPE arising from the interaction of the technology and the consumer distribution is given by

$$
n_{u}=(1-\alpha) \frac{L}{q_{u}}>\frac{L}{q^{*}}
$$


or rewriting

$$
1-\alpha>\frac{q_{11}}{q^{*}}
$$

Thus, a TPE will not exist for large $\alpha$ or a steep average cost curve, $\left(\left(q_{1} / q^{*}\right)\right.$ large $)$. The intuition behind this result is as follows. Suppose the market consists primarily of low cost consumers (large $\alpha$ ). The high-price firms, which sell only to unlucky high-cost consumers, will have a small market. If the average cost curve is steep enough, there will not be enough high-cost consumers to support even one high-price firm. As we will discuss subsequently, if this necessary condition is not met, there will be either no equilibrium or a SPE at the monopoly price, depending on $\left(c_{1}, c_{2}\right)$.

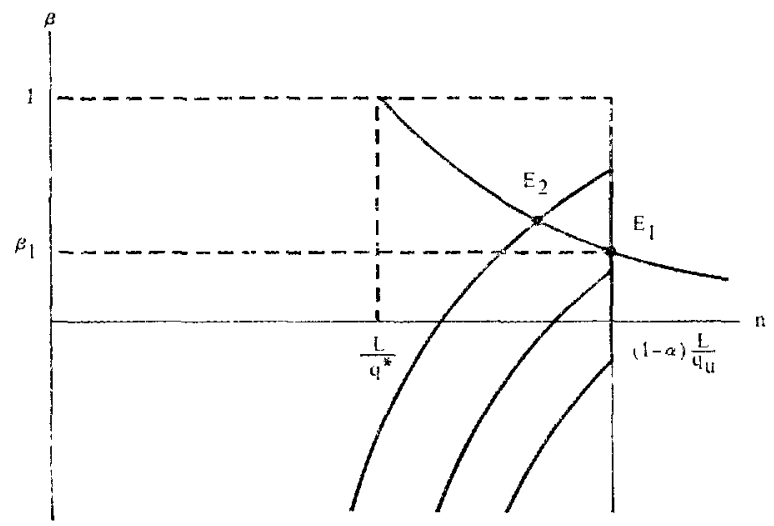

FIGURE 9

$\pi_{\mathrm{l}}=\pi_{l}=\mathbf{0}$.

Assuming that this necessary condition is satisfied, a TPE exists as shown in Figure 9. If the equilibrium occurs at $n_{u}=(1-\alpha) L / q_{u}$ (at a point like $E_{1}$ ), then the high price equals the monopoly price, $u$. If the equilibrium occurs at a point like $E_{2}$, the high price is below the monopoly price. Given the technology, which equilibrium occurs will depend on $c_{2}$. When $\hat{\beta}<0$, we certainly have $E_{1}$, or

$$
p_{h}=u \text { for } c_{2}>u-p^{*} \text {. }
$$

Intuitively, if $c_{2}$ is high enough, each high-price firm can raise its prices without inducing any $c_{2}$ customers to search. Thus, $p_{h}$ will rise until the monopoly price is reached. (For $p>u, c_{2}$ customers will exit from the market. Thus, the rises in $p_{h}$ stop at $u$.)

Referring to (30) and Figure 9, the TPE will occur at $E_{1},\left(\beta=\beta_{1}\right)$, if

$$
p^{*}+\frac{c_{2}}{1-\beta_{1}} \geqq u,
$$

where $\beta_{1}$ is defined by $(31)$ at $n_{u}=(1-\alpha) \frac{L}{q_{u}}$ by

$$
\left(1-\alpha+\frac{\alpha}{\beta_{1}}\right) \frac{L}{n_{u}}=q^{*}
$$

Substituting from $n_{u}$, we have

$$
\beta_{1}=\frac{\alpha}{1-\alpha}\left(\frac{1}{\frac{q^{*}}{q_{u}}-1}\right) .
$$


If the necessary condition given by $(38)$ holds, then $\left(q^{*} / q_{u}\right)-1>\alpha /(1-\alpha)$. This defines a $\beta \in(0,1)$, since $\beta_{1}<1$ follows from (42), and $\beta_{1}>0$ follows from $\left(q^{*} / q_{t}\right)>0$. Substituting (42) into (40), we have

$$
\beta=\beta_{1}, \quad p_{h}=u \quad \text { for } \quad c_{2} \geqq\left(1-\beta_{1}\right)\left(u-p^{*}\right) .
$$

Similarly, from Figure 9,

$$
\beta>\beta_{1}, \quad p_{k}<u, \text { for } c_{2}<\left(1-\beta_{1}\right)\left(u-p^{*}\right),
$$

i.e. for smaller $c_{2}$, we have an equilibrium like $E_{2}$.

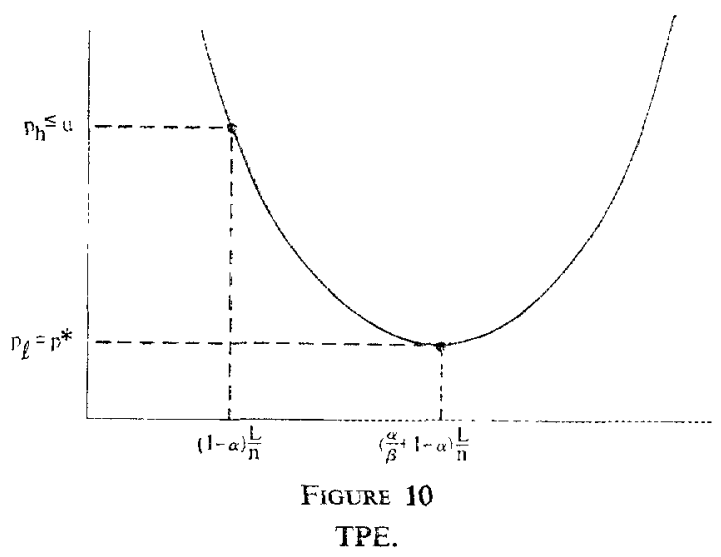

Substituting into (26) and (27), we may calculate the number of firms. We have

$$
n=(1-x) \frac{L}{q_{h}}
$$

We now confirm that these equations do define a full TPE. That is, we must show that in fact consumers are searching optimally, every firm is making zero profits, and every firm is maximizing profits.

(i) Search Equilibrium. From Lemmas 3 and $4, c_{2} \geqq \bar{p}-p^{\mathrm{min}}$. Thus, $c_{2}$ consumers find it optimal to purchase randomly. At the $p_{h}<u$ TPE, since the $c_{2}$ 's are indifferent to search, then $c_{1}$ consumers do prefer to gather information, since $c_{1}<c_{2}$. At the $p_{h}=u$ TPE, the necessary condition that the $c_{1}$ consumers do gather information is, of course, just opposite of the condition that the $c_{2}$ consumers do not search.

$$
\begin{aligned}
& c_{1}<\left(1-\beta_{1}\right)\left(u-p^{*}\right) \\
& c_{2} \geqq\left(1-\beta_{1}\right)\left(u-p^{*}\right) .
\end{aligned}
$$

(ii) Zero Profits. By setting price equal to average cost, the TPE was constructed to obey the zero profit conditions.

(iii) Maximum Profits. We now show that no potentially deviant $p_{l}$ or $p_{h}$ firm can increase its profits by charging a different price. We examine a $p_{l}$ deviant first.

Suppose a $p_{l}$ deviant raises his price. The mean price $\bar{p}$ will rise without affecting $p^{\text {min }}$, raising the benefits of search. Since the $c_{1}$ consumers were already searching, their behaviour will not change. The $c_{2}$ consumers could be induced to search. If they do, they will purchase from the non-deviant $p_{l}$ firms. The $p_{l}$ deviant's sales will fall to zero. Thus, $P_{i}$ deviance is unprofitable.

Suppose a $p_{h}$ deviant lowers his price to $p_{d}<p_{h}$. The mean price falls without affecting $p^{\text {min }}$. This lowers the benefits from search. Since the $c_{2}$ consumers previously found it non-optimal to search, their behaviour is not affected. However, it is possible that the 
benefits fall enough to make search by the $c_{1}$ consumers non-optimal. If they begin purchasing randomly, the $p_{\mathfrak{h}}$ devianı's sales rise from $(1-\alpha) L / n$ to $q_{d}=(L / n)$.

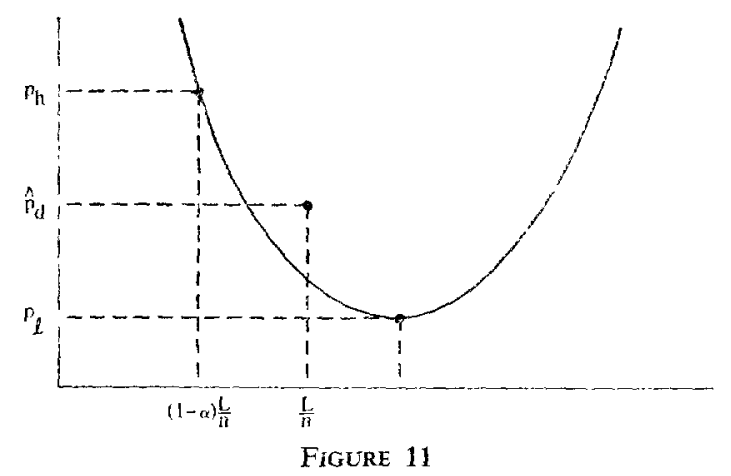

TPE broken.

Thus, if the $\hat{p}_{d}$ which eliminates search is high enough for the deviant to cover his average costs, large $p_{k}$ deviance will be profitable and the TPE will be broken. This situation is shown in Figure 11 . The necessary condition for such "global" $p_{h}$ deviance to be unprofitable is given by

$$
\hat{p}_{d}<A\left(\frac{L}{n}\right)
$$

where $\hat{p}$ is the price such that

$$
\bar{p}^{\prime}-p^{\min }=c_{1},
$$

where

$$
\bar{p}^{\prime}=\beta p^{*}+\left(1-\beta-\frac{1}{n}\right) p_{k}+\frac{1}{n} \hat{p}_{d} .
$$

Substituting (49) into (48) and using Lemmas 3 and 4, we have

$$
\hat{p}_{d}=\left\{\begin{array}{l}
p_{h}-n\left(c_{2}-c_{1}\right) \text { for } p_{h}<u \\
p_{h}-n\left[\left(1-\beta_{1}\right)\left(u-p^{*}\right)-c_{1}\right] \text { for } p_{h}=u .
\end{array}\right.
$$

For large values of $L, n$ will be large and (47) will be satisfied. Intuitively, if there are many firms, a $p_{h}$ deviant will have a very small effect on the average price; thus, it will be unable to stop the $c_{1}$ consumers from gathering information. Note that this condition assumed that only one firm deviated. If a significant number of $p_{h}$ firms colluded in jointly lowering price, they could break the TPE more easily. This raises the possibility that duopoly may lead to lower prices than competition.

We have derived regions of $\left(c_{1}, c_{2}\right)$ under which there are SPE, TPE and no equilibria. We summarized these regions in Figure 1. Under the assumption that $L \rightarrow \infty$, the regions do not overlap and the equilibrium (if it exists) is unique for all $c_{2} \geqq c_{1} \geqq 0 .{ }^{12}$

If the technology is such that $\beta_{1} \geqq 1$ (i.e. $\left.1-\alpha \leqq\left(q_{a} / q^{*}\right)\right)$, there is a SPE at $p=u$ for $c_{1}, c_{2} \geqq u-p^{*}$ and no equilibrium for lower $c_{1}, c_{2} \cdot{ }^{3}$

\section{Non-existence of Equilibrium}

For certain values of $\left(\alpha, q_{u}, q^{*}, c_{1}, c_{2}\right)$ we have shown that no equilibrium exists, because if some deviant changes his price substantially, he will earn positive profits. If firms engaged only in "local" price experiments, but not in "global" price experiments, the nonexistence region would not occur. Alternatively, if the deviant realizes that others will react to his deviance, then he may not break the equilibrium. With this in mind, a "limit 
price" equilibrium concept can be defined as follows. There exists some price $p^{L}$ and associated quantity $q^{L}$ for every firm such that (i) profits are zero, (ii) no deviant can break the equilibrium with price decreases and (iii) if any firnt attempts to increase short-run profits by raising price, another deviant can lower its price discretely and capture all the $\mathfrak{c}_{1}$ consumers (and possibly the $c_{2}$ consumers as well). Thus, this limit price equilibrium is a reaction function equilibrium.

$p^{L}$ is derived as follows for the case in which $c_{1}=c_{2}=c .^{14}$

$$
\begin{aligned}
p^{L} & =A\left(q^{L}\right) . & & \text { (zero profits) } \\
q^{L} & =\frac{L}{n} . & & \text { (equal market shares) } \\
\frac{n-1}{n}\left(p^{L}-p^{*}\right) & =c . & & \text { (search equilibrium) }
\end{aligned}
$$

Equation (53) expresses the notion that if some deviant lowers price to $p^{*}$, he will just induce search. Rewriting, we have

$$
p^{L}=p^{*}+\frac{n}{n-1} c
$$

where $(51)$ and (52) define $n$. For large $n, n /(n-1) \cong 1$, and we have

$$
p^{L} \cong p^{*}+c \text {. }
$$

Note that $p^{L}$ is not a "Nash" equilibrium with respect to deviant price increases. A single firm could raise price slightly without losing any customers. However, this would then induce another deviant to lower price. That is, if a firm acts in its short-rin interest, it will destroy the equilibrium by allowing other firms drastically to cut prices to induce search. Prices may then begin to oscillate between the competitive price $p^{*}$ and the limit price. The exact dynamics will depend on the dynamic learning process of consumers and firms. In general, prices may creep up slowly to slightly above the limit price, inducing a price war down to $p^{*}$, only to again begin the upward creep. The frequency and regularity of the cycle will depend on the adjustment speeds of price changes, entry, and the learning by consumers. In that smaller more competitive firms will be more likely to act in their short-run interests at the expense of the long-run, this leads to the notion that competitive markets will be more unstable than oligopolistic markets.

\section{CONCLUSIONS}

In this paper, we have analysed the industry equilibrium for an economy in which imperfectly informed consumers can only become perfectly informed at a cost. This assumption leads to a monopolistically competitive equilibrium and generally to price dispersion as well, even though the commodity produced by each firm is identical.

The price dispersion here is different from that analysed by Grossman and Stiglitz [5] and Mortensen [6], where costly information leads to incomplete market adjustments to exogenous shocks. Such markets are incompletely arbitraged. Furthermore, the price dispersion generated here is specifically associated with a market economy; a socialist economy with exactly the same information and production technology would require all stores to charge the same price.

This paper is one of a series dealing with the effects of costly information on market equilibrium. These studies differ with respect to the technology of information acquisition and the characteristics of consumers and producers. In the model examined here, consumers differ only in their costs of information acquisition. In Salop [10] and Salop and Stiglitz [13] individuals differ also in their demand functions. A further reason for price dispersion arises there. Firms attempt to act as discriminating monopolists. The costs of 
information allows them to exercise this kind of discrimination, which they would be unable to do in a competitive market with perfect information. Finally, in Salop and Stiglitz [13], Butters [3] and Stiglitz [17], even when individuals are identical ex ante in both search costs and demand functions, price dispersion may occur.

Finally, one shortcoming with this model is that possible "indirect information" contained in the prices and market shares are ignored by consumers. Low-priced stores have larger market shares, since they sell to informed as well as uninformed buyers. If uninformed buyers observed the market shares of firms, then purchasing according to market shares would assure then the lower price. This is an example of the more general notion that in the presence of some informed consumers, uninformed consumers ought to "buy with the market"; price will reflect quality and market shares will reflect the overall "best buys" 15

If there is no heterogeneity in preferences, advertising, or differential costs of production, this result is true in our model. However, in general there will be other "noise" in the market so that there is still a net benefit to becoming informed; Grossman and Stiglitz have shown that generally an equilibrium with price dispersion will still obtain.

\section{First version received April 1975; final version accepted October 1976 (Eds.).}

The views expressed herein are those of the authors and do not neccssarily represent the views of the Board of Governors of the Federal Reserve System. We are grateful to Avi Braverman, Andy Weiss, Larry Weiss and other participants at the IMSSS Conference at Stanford University and Steve Salant, Perer von zur Muehlen and Roger Waud at the Federal Reserve Board for helpful conversations. Stiglitz's work was supported by National Science Foundation Grant No. SOC74-22182 at the Institute for Mathematical Studies in the Social Sciences, Stanford University.

\section{NOTES}

1. $u$ may be thought of as the marginal utility in dollar terms of the unit of the durable.

2. Cf. G. Butters [3], P. von zur Mueblen [18], Stiglitz [17] and Salop and Stiglitz [13]. The basic result on the existence of equilibrium with price distributions remains valid in these models.

3. Note that $\bar{p}$ is not weighted by sales of each store. It is not the mean price measured in the price dispersion literature. For a model in which consumers know market shares, see Smallwood and Conlisk [15].

4. Risk aversion is effectively captured in $c^{i}$.

5. If $E_{\mathrm{S}}^{i}=E_{N}^{i}$, the consumer is just indifferent. We follow the convention that indifferent consumers do not buy the newspaper. This assumption is not crucial. If the opposite convention were followed or it were assumed indifferent consumers flipped a coin, the equilibrium prices would change only by an arbitrarily small epsilon.

6. Its output is the lower of the two outputs which share a common AC. Thus, each firm's output is demand-constrained at equilibrium (it would like to sell more if it could) unless the firm charges the competitive price.

7. More precisely, we have, for a finite $n^{*}$,

$$
\begin{aligned}
& \pi\left(\hat{p}_{j} \mid \hat{p}^{-j}\right) \geqq 0, \text { for all } j=1,2, \ldots, n^{*} \\
& \pi\left(\hat{p}_{j} \mid \hat{p}^{-j}\right) \leqq 0, \text { for all } j=1,2, \ldots, n^{*}+1 .
\end{aligned}
$$

8. If no consumers search, every firm has identical sales and the $p_{h}$ firm has highest profits. If consumers all search, the $p_{m}$ and $p_{h}$ firms have no sales at all.

9. It is possible that $q_{d}$ is so large that $p_{d}<A C\left(q_{d}\right)$. That is, the deviant is swamped with customers. This is a potential problem for any competitive model. Cf. Salop [11].

10. With downward-sloping demand curves, this would be at the Chamberlinean monopolistically competitive price. See Braverman [2].

11. We assume $L$ is very large so as to not bias the case against perfect competition. Once again, we ignore the fact that the deviant will be swamped with customers.

12. For finite $L$, there are regions in which both a SPE at $u$ and a TPE exist. See equations (16) and (46).

13. We effectively move the axes of Figure 1 over to $\left(1-\beta_{1}\right)\left(u-p^{*}\right)$.

14. Note that if $c_{1}=c_{2}$, a TPE must have the property that all consumers are just indifferent to search. If we follow the convention that indifference implies no search, then a TPE is impossible. On the other hand, if we assume that an indifferent consumer chooses to search with probability $\alpha$, then a different TPE obtains for each $\alpha$. For an example of such a model, see Stiglitz [17]. Shilony [14] derives a similar mixed strategy equilibrium.

15. This has been explored by Nelson [7] and Smallwood and Conlisk [15]. 


\section{REFERENCES}

[1] Akerlof, G. "The Market for "Lemons": Qualitative Uncertainty and the Market Mcchanism ", Quarterly Joumal of Economics (1970).

[2] Bravernan, A. "Price Dispersion in Monopolistic Competition" (Ph.D. Dissertation, Stanford University, 1976).

[3] Butters, G. "Equilibrium Distributions of Sales and Advertising Prices", (this volume).

[4] Diamond, P. "A Model of Price Adjustment", Joumal of Economic Theory (1971).

[5] Grossman, S. and Stiglitz, J. "Information and Competitive Price Systems", American Economic Review, Papers and Procedings (May 1976).

[6] Mortensen, D. T. "Search Equilibrium in a Simple Multi-Market Economy" (Center for Mathematical Studies, Discussion Paper No. 54, Northwestern University, October 1973).

[7] Nelson, P. "Information and Consumer Behavior", Joumal of Economic Theory (1970).

[8] Phelps, E. and Winter, S. "Optimal Price Policy Under Atomistic Competition", in Phelps, E., et al, Microeconomic Foundations of Inflation and Employment Theory (New York, 1970).

[9] Rothschild, M. "A Two-Armed Bandit Theory of Market Pricing", Jounal of Econonic Theory (1974).

[10] Salop, S. "The Noisy Monopolist", (this volume).

[11] Salop, S. "On the Non-Existence of Competitive Equilibrium" (Federal Reserve Board, 1976).

[12] Salop, S. and Stiglitz, J. "A Framework for Analyzing Monopolistically Competitive Price Dispersion " (Federal Rescrve Board, 1975).

[13] Salop, S. and Stiglitz, J. "A Theory of Sales" (Stanford University, 1976).

[14] Shilony, Y. "Mixed Pricing in Locational Oligopoly", (Berkeley, 1975).

[15] Smallwood, D. and Conlisk, J. "Produce Quality in Markets Where Consumers are Imperfectly Informed and Naive" (UCSD, 1975).

[16] Stigler, G. "The Economics of Information ", Jourtal of Poitical Economy (1961).

[17] Stiglitz, J. "Equilibrium Wage Distributions" (Technical Report No. 154, Economics Saries, Institute for Mathematical Studies in the Social Science, Stanford University, 1974).

[18] von zur Muehlen, P. "Sequential Search and Price Dispersion in Monopolistic Competition", (Federal Reserve Board, 1976). 
(C) 1977 Review of Economic Studies Ltd 